CLINICAL STUDY

\title{
Changes in C-reactive protein levels before type 2 diabetes and cardiovascular death: the Whitehall II study
}

\author{
A G Tabák ${ }^{1,2}$, M Kivimäki $^{1}$, E J Brunner ${ }^{1}$, G D Lowe ${ }^{3}$, M Jokela ${ }^{1,4}$, T N Akbaraly ${ }^{1,5}$, A Singh-Manoux ${ }^{1,6}$, \\ J E Ferrie ${ }^{1}$ and D R Witte ${ }^{1,7}$ \\ ${ }^{1}$ Department of Epidemiology and Public Health, University College London, 1-19 Torrington Place, London WC1E 6 BT, UK, ${ }^{2}$ First Department of \\ Medicine, Faculty of Medicine, Semmelweis University, Budapest H-1083, Hungary, ${ }^{3}$ Division of Cardiovascular and Medical Sciences, University of \\ Glasgow, Glasgow G11 6NT, UK, ${ }^{4}$ Department of Psychology, University of Helsinki, Helsinki FI-O0014, Finland, ${ }^{5}$ U888 INSERM, 34093 Montpellier, \\ France, ${ }^{6}$ U687 INSERM, AP-HP, Villejuif 94807, France and ${ }^{7}$ Steno Diabetes Center, Gentofte DK-2820, Denmark
}

(Correspondence should be addressed to A G Tabák at Department of Epidemiology and Public Health, University College London; Email: a.tabak@ucl.ac.uk)

\begin{abstract}
Objective: Prospective studies show that high C-reactive protein (CRP) levels predict diabetes and cardiovascular disease (CVD), but changes in this marker preceding disease onset are not well characterized. This study describes CRP trajectories prior to type 2 diabetes onset and fatal CVD. Methods: In a prospective cohort of 7350 British civil servants (70\% male, mean age 51 years), 558 incident type 2 diabetes cases (75-g oral glucose tolerance test, doctor's diagnosis, or self-report) and 125 certified fatal cardiovascular events were observed during a median follow-up of $>14$ years. Trajectories of logarithmically transformed CRP levels prior to incident diabetes or fatal cardiovascular event (cases), or the end of follow-up (controls) were calculated using multilevel modeling.

Results: Baseline CRP levels were higher among participants who developed diabetes (median (interquartile range) $1.44(2.39)$ vs $0.78(1.21) \mathrm{mg} / \mathrm{l})$ or fatal CVD (1.49 (2.47) vs $0.84(1.30) \mathrm{mg} / \mathrm{l})$ compared with controls (both $P<0.0001$ ). In models adjusted for age, sex, body mass index, ethnicity, and employment grade, CRP levels increased with time among both incident diabetes cases and controls $(P<0.0001)$, but this increase was less steep for cases group $(P<0.05)$. CRP levels followed increasing linear trajectories in fatal cardiovascular cases and controls $(P<0.0001)$ with no slope difference between the groups.

Conclusions: CRP levels were higher among those who subsequently developed diabetes or died from CVD. For type 2 diabetes, age-related increase in CRP levels was less steep in the cases group than in controls, whereas for fatal CVD these trajectories were parallel.
\end{abstract}

European Journal of Endocrinology 163 89-95

\section{Introduction}

Prospective epidemiological studies show that elevated C-reactive protein (CRP) levels within the normal range predict the development of incident type 2 diabetes mellitus (DM; 1-8) and cardiovascular disease (CVD) $(9,10)$. The association between low-grade inflammation and obesity-related pathologies (metaflammation) suggests that low-grade inflammation may be "common soil' for the development of type 2 diabetes and CVD (11). However, it remains unclear whether CRP has an independent role in diabetes $(1,4,6)$ or $\operatorname{CVD}(9,10,12)$, as the initial associations showed considerable attenuation after adjustment for potential confounders in some studies, and Mendelian randomization studies, using common genetic variants linked to higher CRP levels as a way to reduce the problem of potential confounders and bias (13), have not provided consistent support for a causal relation of CRP to diabetes (14-16), or CVD outcomes (17-20). To increase the understanding of the role of CRP levels in the natural history of these diseases, we set out to describe the population trajectories of CRP levels (measured by a high sensitivity assay) in the years before the development of type 2 diabetes and before fatal CVD, comparing them with the CRP trajectories in controls.

\section{Subjects and methods}

\section{Participants and design}

Participants were from the Whitehall II study. All nonindustrial civil servants who were 35-55 years of age working in the London offices of 20 departments were invited to participate in this study; 10308 participants (6895 men) were recruited between 1985 and 1988 (Phase 1) (21). During Phase 3 of the study in 19911993, all participants known to be alive and in the country were invited to the screening clinic to undergo 
a 75-g oral glucose tolerance test (OGTT); 6058 men and 2758 women $(85.5 \%$ of the original sample) attended the clinic. This was the first study phase where an OGTT and lipid profiles were assessed, and is therefore regarded as the baseline for these analyses. Screening was repeated during Phase 5 (1997-1999; 5444 men and 2385 women participated) and Phase 7 (2003-2004; 4894 men and 2074 women). Additional questionnaire-only phases assessed diabetes status during Phase 4 (1995-1996; 5928 men and 2700 women), Phase 6 (2001; 5151 men and 2204 women), and Phase 8 (2006; 5017 men and 2156 women). The University College London ethics committee reviewed and approved the study, and written informed consent was obtained from each participant at each phase.

\section{Measurements}

C-reactive protein $\mathrm{CRP}$ was measured in serum stored at $-80{ }^{\circ} \mathrm{C}$ using a high-sensitivity immunonephelometric assay in a BN ProSpec nephelometer (Dade Behring, Eschborn, Germany) using samples from Phase 3 and Phase 7 of the study. Values below the detection limit $(0.154 \mathrm{mg} / \mathrm{l}$, multiplied by 9524 in order to express the value in mmol/l) were assigned a value of $0.077 \mathrm{mg} / \mathrm{l}$. Samples from both study phases that were 10 years apart were analyzed at the same time. Intra- and interassay coefficients of variation were 4.7 and $8.3 \%$ respectively. We excluded all observations with CRP level $>10 \mathrm{mg} / \mathrm{l}$ to exclude cases of possible acute inflammation.

Diabetes Diabetes was defined by a fasting glucose $\geq 7.0 \mathrm{mmol} / \mathrm{l}$ or a $2 \mathrm{~h}$ postload glucose $\geq 11.1 \mathrm{mmol} / \mathrm{l}$ using a 75 -g OGTT (22). Venous blood samples were taken in the fasting state ( $\geq 5 \mathrm{~h}$ of fasting) before undergoing a standard 2-h OGTT. Glucose was measured in fluoride plasma by an electrochemical glucose oxidase method. By the end of the median 14.1 (interquartile range (IQR) - 3.0) years of diabetes follow-up, 558 incident diabetes cases had been identified: 261 were identified by 75-g OGTT at screening, and 297 were identified either by self-report of doctor diagnosis $(n=205)$ or by use of diabetic medication $(n=92)$.

Cardiovascular mortality of the 10308 participants at baseline, $99.9 \%(n=10297)$ have been followed up for mortality through the National Health Services Central Registry. Participants in the present study were followed for mortality up to 31st January 2008 or their date of death $(n=847)$, embarkation $(n=84)$, or deregistration with a health authority $(n=176)$. Registration of death within 5 days is a legal requirement in the UK, so participants who were not included in the above categories can be assumed to be alive. Death certificates were coded according to the 9th and 10th revisions of the International Classification of Disease (ICD) and were categorized as CVD for ICD-9 codes 340-459 or ICD-10 I00-I99, and non-CVD for all other codes. During the median 15.7 (IQR - 0.7) years of mortality follow-up, altogether 125 cardiovascular and 305 non-cardiovascular deaths were registered.

Other covariates The following variables were considered as time-invariant covariates: sex, age at the end of follow-up, ethnicity, and civil service employment grade (as a marker of socio-economic position). These data were derived from Phase 3 or Phase 1 questionnaires. Ethnicity was coded in two categories (white and non-white), and employment grade was coded in three categories (administrative, executive and support). All other variables were assessed contemporaneously with CRP measurements and were coded as timevarying covariates. Body mass index (BMI, $\mathrm{kg} / \mathrm{m}^{2}$ ) was calculated from standardized measurements of weight and height. Systolic blood pressure was measured with the Hawksley random zero sphygmomanometer (Phase 3) and with an Omron HEM 907 (Phase 7); the measurement used was the average of two readings taken in the sitting position after 5 min rest. Total cholesterol and high-density lipoprotein (HDL)-cholesterol were measured within $72 \mathrm{~h}$ in serum stored at $4{ }^{\circ} \mathrm{C}$ using enzymatic colorimetric methods. Use of blood pressure lowering medication and lipid lowering medication was identified from questionnaire data. Cigarette smoking was categorized as current smoker/ non-smoker at the time of the CRP measurement. Self-reported leisure-time physical activity was categorized as vigorous ( $\geq 1 \mathrm{~h}$ vigorous activity/week), moderate ( $\geq 1 \mathrm{~h}$ moderate but $<1 \mathrm{~h}$ vigorous activity/ week), and none/mild $(<1 \mathrm{~h}$ vigorous or moderate activity/week). Dietary patterns were assessed via questions on the frequency of fruit and vegetable consumption, and the type of bread and milk consumed. A dietary score was then calculated and classified into three categories (unhealthy/moderately healthy/ healthy) as described previously (23).

\section{Statistical analysis}

Statistical analyses were undertaken using SPSS 14.0 statistical software (SPSS Inc., Chicago, IL, USA), and statistical significance was inferred at a two-tailed $P<0.05$. Two separate sets of analyses were performed, one for incident diabetes and another for CVD death. For the incident diabetes outcome, we excluded nonresponders in Phase $3(n=1492)$, individuals with prevalent diabetes during Phase $3(n=42)$, with no follow-up data for incident diabetes $(n=552)$, with missing CRP values $(n=549)$, with elevated CRP values (CRP $>10 \mathrm{mg} / \mathrm{l}, n=90)$, or with any other missing covariates $(n=250)$, leaving a final analytical sample of 7333 subjects $(71.1 \%$ of the original sample).

For fatal CVD outcome, we excluded non-responders during Phase $3(n=1492)$, participants with missing cause-specific mortality data $(n=17)$, with missing CRP 
values $(n=627)$, with elevated CRP values (CRP> $10 \mathrm{mg} / \mathrm{l}, n=105)$, or with any other missing covariates $(n=300)$. Thus, the final analytical sample for fatal CVD consisted of 7761 subjects $(75.3 \%$ of the original sample).

Owing to the skewed distribution of CRP values, all analyses use $\log _{2}$-transformed CRP values. For each of our two outcomes, we divided participants into two groups separately: those who developed (cases) and those who did not develop (the controls) the outcome of interest (incident diabetes or CVD death) during the follow-up. We centered time around the date of event for cases and at the last screening or questionnaire phase for controls. Participants were then tracked backwards to the first clinical screening when a CRP measurement was obtained. For example, a participant who reported diagnosed diabetes during Phase 8 has his time 0 at the midpoint of Phase 7 and Phase 8 (estimated time of diagnosis), and has two CRP measurements: one during Phase 7 , approximately -1 year to the event and another during Phase 3, approximately -11 years to event. As indicated in the tables associated with Fig. 1, the CRP measurements were well distributed throughout the 14-year time window of the study (i.e. at screening dates or between the screenings).

We used multilevel longitudinal modeling to estimate CRP trajectories (24). Data were structured so that measurement times (observations) were nested within subjects, and the non-independence of the observations (the same individuals contributed to more than one observation in the dataset) was taken into account in estimating s.E.M. Differences in CRP trajectories between cases and controls were modeled using a linear growth model with two steps of adjustment for covariates. First, we adjusted for age at the end of follow-up, sex, ethnicity, civil service grade (all time-invariant covariates), and BMI (a time-varying covariate). Secondly, we adjusted for systolic blood pressure, use of blood pressure lowering medication, total and HDL-cholesterol, use of lipid lowering medication, smoking, leisure-time physical activity, and dietary patterns (all time-varying covariates). Finally, we conducted sensitivity analyses (adjusted for age at the end of follow-up, sex, ethnicity, civil service grade, and BMI) including only participants with exactly two CRP measurements before the end of follow-up.

For time-invariant covariates, we checked for main effects and their interaction with time, and retained only the covariates leading to the most parsimonious model (sex as main effect, ethnicity $X$ time interaction for DM and CVD mortality) and the lowest information criteria. We also tested for possible three-way interactions between the time-invariant covariates in order to exclude heterogeneity in the CRP trajectories; all these interaction terms were nonsignificant at $P>0.05$ and were therefore deleted from the models. Time-varying covariates were entered into the models only as main effects.

At each step of adjustment, caseness of interest (incident diabetes or CVD death) was entered into the model as a main effect to examine whether cases differed from controls in average levels of CRP. We examined CRP trajectories over time by entering the interaction term between time and caseness into the model.
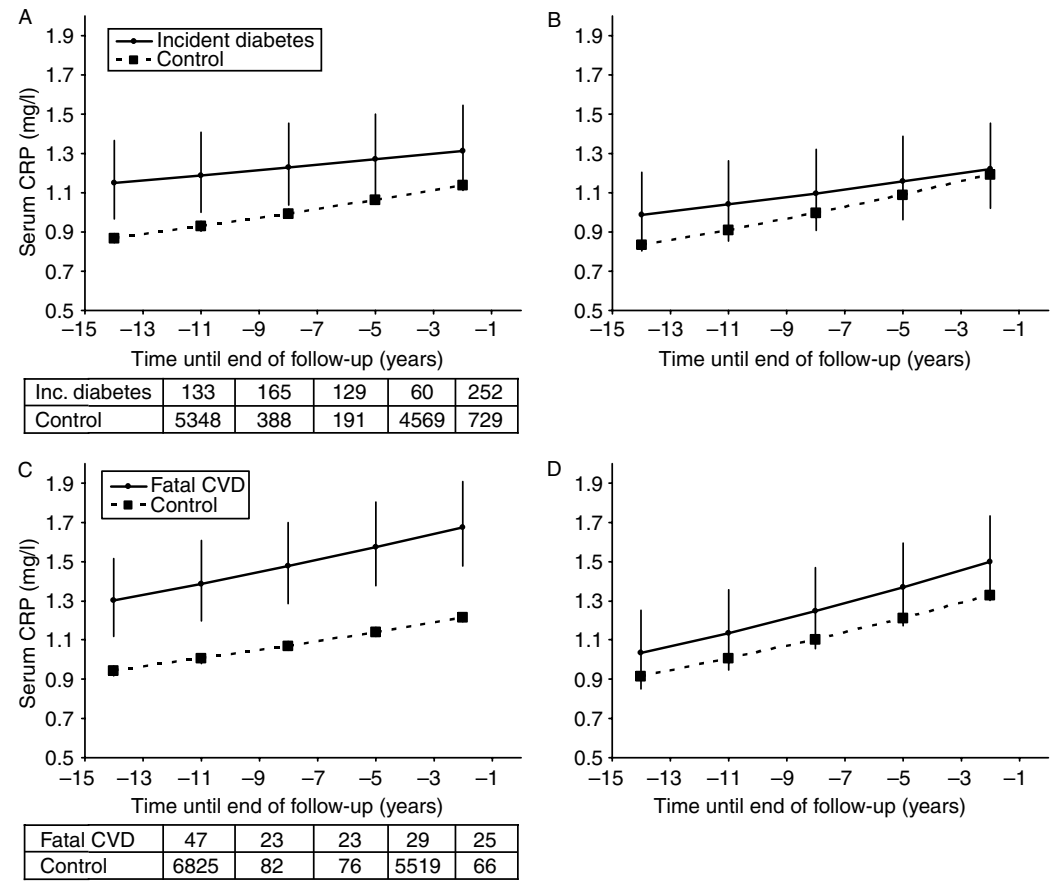

Figure 1 Trajectories of back-transformed CRP values before diagnosis of diabetes mellitus or the end of follow-up in 558 cases compared to 6775 controls (A and B), and before fatal cardiovascular event or the end of follow-up in 125 cases compared to 7636 controls ( $C$ and $D)$. Multilevel longitudinal modeling was done using linear growth model. Error bars show $95 \%$ confidence intervals for the fixed effects. Trajectories were fitted for a hypothetical population of 65 years of age at the end of follow-up (CVD death/incident diabetes resp.), $91 \%$ white, $29 \%$ female, with a BMl of $25.8 \mathrm{~kg} / \mathrm{m}^{2}$ (A and C), and additionally with a systolic blood pressure of $124 \mathrm{mmHg}$, total cholesterol of $6.2 \mathrm{mmol} / \mathrm{l}$, HDL-cholesterol of $1.5 \mathrm{mmol} / \mathrm{l}$, with $14 \%$ on blood pressure lowering medications, $5 \%$ on lipid lowering medications, and $10 \%$ on smoking ( $B$ and $D$ ). Tables show the number of measurement for each period before incident diabetes/end of follow-up (A) or CVD death/end of follow-up (C). 


\section{Results}

The 558 incident diabetic cases provided a total of 739 CRP measurements (377 subjects with one measurement and 181 with two measurements). For the 6775 controls, the corresponding number was 11225 measurements (2325 subjects with one measurement and 4450 with two measurements). As expected, incident diabetes cases were older, more frequently from ethnic minorities, more likely to be smokers and followed an unhealthy dietary pattern, less physically active, from lower employment grades, and on antihypertensive medication. They also had higher BMI, systolic blood pressure, total cholesterol and CRP, and lower HDLcholesterol values at baseline (all $P<0.05$; Table 1 ).

The 125 cases of fatal CVD provided a total of 147 CRP measurements (103 subjects with one visit and 22 with two visits). For the 7636 controls, the corresponding number was 12568 measurements (2704 subjects with one visit and 4932 with two visits). Fatal CVD cases showed similar differences compared with controls and incident diabetes cases except that they were more likely to be men $(P<0.05)$, and were not significantly different from controls regarding civil service grade and physical activity $(P>0.05$; Table 1$)$.

\section{CRP trajectories in incident diabetes cases before diagnosis}

Analysis adjusted for demographic covariates and BMI showed a convergence of the log-transformed CRP trajectories for incident diabetes cases and controls with a significant time $\times$ event interaction $(-0.016$ (s.E.M. 0.008) $\log _{2}(\mathrm{mg} / \mathrm{l}) /$ year), indicating significantly different slopes among cases and controls. The difference in CRP level was smallest at the end of follow-up: 0.17 (s.e.M. 0.08) $\log _{2}(\mathrm{mg} / \mathrm{l}$ ) compared with 0.41 (s.E.M. 0.09) $\log _{2}(\mathrm{mg} / \mathrm{l}) 14$ years earlier. After further adjustment for systolic blood pressure, use of antihypertensive and lipid lowering medication, blood lipids and lifestyle characteristics, the difference at the end of follow-up became non-significant, while the time $\times$ event interaction remained significant: -0.017 (s.E.M. 0.006) $\log _{2}(\mathrm{mg} / \mathrm{l}) /$ year). The sensitivity analysis on 181 cases and 4450 controls with two measurements of CRP confirmed a narrowing difference in the log-transformed CRP levels between cases and non-cases during follow-up (Table 2). When the CRP values were back transformed, these models translated to converging CRP trajectories for incident diabetes cases and controls over the time window of the study (Fig. 1).

\section{CRP trajectories in fatal CVD cases}

The trajectories of log-transformed CRP for fatal CVD cases and controls, adjusted for demographic covariates and BMI, were parallel without any significant time $\times$ event interaction. The mean difference during the follow-up between the $\log _{2}$-transformed CRP of cases and controls was 0.46 (s.E.M. 0.12$) \log _{2}(\mathrm{mg} / \mathrm{l})$, highly significant throughout the follow-up period.

Table 1 Baseline characteristics of incident diabetes and fatal cardiovascular cases and respective controls included in the trajectory analysis. Data are presented as mean \pm s.D. or \%.

\begin{tabular}{|c|c|c|c|c|}
\hline Variable & Control & Incident diabetes & Control & Fatal CVD \\
\hline$n$ & 6775 & 558 & 7636 & 125 \\
\hline Age (years) & $50.6 \pm 6.7$ & $52.0 \pm 6.4^{\ddagger}$ & $50.7 \pm 6.6$ & $54.4 \pm 5.3^{\ddagger}$ \\
\hline Male (\%) & 70.2 & 67.7 & 69.5 & $80.8^{\dagger}$ \\
\hline White (\%) & 92.6 & $81.4^{\ddagger}$ & 91.0 & $80.8^{\ddagger}$ \\
\hline \multicolumn{5}{|l|}{ Employment grade (\%) } \\
\hline Administrative & 40.5 & 27.6 & 38.8 & 34.4 \\
\hline Executive & 45.0 & 50.7 & 45.3 & 43.2 \\
\hline Support & 14.5 & 21.7 & 15.9 & 22.4 \\
\hline Body mass index $\left(\mathrm{kg} / \mathrm{m}^{2}\right)$ & $25.1 \pm 3.5$ & $27.6 \pm 4.7^{\ddagger}$ & $25.3 \pm 3.7$ & $26.2 \pm 4.1^{*}$ \\
\hline Systolic blood pressure $(\mathrm{mmHg})$ & $121 \pm 14$ & $126 \pm 15^{\ddagger}$ & $121 \pm 14$ & $127 \pm 15^{\ddagger}$ \\
\hline Antihypertensive medication (\%) & 6.8 & $13.1^{\overline{1}}$ & 7.6 & $22.4^{\bar{f}}$ \\
\hline Total cholesterol $(\mathrm{mmol} / \mathrm{l})$ & $6.4 \pm 1.1$ & $6.7 \pm 1.1^{\ddagger}$ & $6.4 \pm 1.1$ & $7.0 \pm 1.4^{\ddagger}$ \\
\hline HDL-cholesterol $(\mathrm{mmol} / \mathrm{l})$ & $1.5 \pm 0.4$ & $1.3 \pm 0.4^{\ddagger}$ & $1.4 \pm 0.4$ & $1.3 \pm 0.5^{\ddagger}$ \\
\hline Lipid lowering medication (\%) & $1.4^{-}$ & 1.6 & 1.6 & 2.4 \\
\hline Current smoker (\%) & 12.4 & $16.3^{*}$ & 12.7 & $23.2^{\dagger}$ \\
\hline \multicolumn{5}{|l|}{ Physical activity (\%) } \\
\hline Vigorous & 18.0 & 13.6 & 17.3 & 10.4 \\
\hline Moderate & 47.4 & 46.6 & 47.4 & 52.0 \\
\hline None/mild & 34.7 & 39.8 & 35.4 & 37.6 \\
\hline \multicolumn{2}{|l|}{ Dietary score } & $-^{\star}$ & & $-^{\dagger}$ \\
\hline Healthy & 12.8 & 12.4 & 12.6 & 8.0 \\
\hline Moderately healthy & 81.7 & 79.2 & 81.6 & 79.2 \\
\hline Unhealthy & 5.5 & 8.4 & 5.8 & 12.8 \\
\hline $\mathrm{CRP}(\mathrm{mg} / \mathrm{l})^{\mathrm{a}}$ & $0.78(1.21)$ & $1.44(2.39)^{\ddagger}$ & $0.84(1.30)$ & $1.49(2.47)^{\ddagger}$ \\
\hline
\end{tabular}

Comparisons were done using two-sample $t$-tests, Mann-Whitney $U$ tests, or Fisher's exact tests as appropriate. ${ }^{*} P<0.05,{ }^{\dagger} P<0.01,{ }^{\ddagger} P<0.0001$ between respective cases and control.

${ }^{a}$ Median (interquartile range). 
Table 2 Fixed effects for the multilevel models of change for $\log _{2}$-transformed C-reactive protein (CRP) before diagnosis of diabetes (DM) (558 cases and 6775 controls) and fatal cardiovascular event (cardiovascular disease (CVD); 125 cases and 7636 controls), or the end of follow-up.

\begin{tabular}{|c|c|c|c|c|}
\hline & \multicolumn{2}{|c|}{ Incident DM } & \multicolumn{2}{|c|}{ CVD death } \\
\hline & $\begin{array}{l}\text { Regression } \\
\text { coefficient }\end{array}$ & S.E.M. & $\begin{array}{l}\text { Regression } \\
\text { coefficient }\end{array}$ & S.E.M. \\
\hline \multicolumn{5}{|l|}{ Model 1} \\
\hline Time (per year) & $0.024^{\S}$ & 0.005 & $0.021^{\S}$ & 0.004 \\
\hline Case & $0.17^{\star}$ & 0.08 & $0.46^{\ddagger}$ & 0.12 \\
\hline Case $\times$ time & $-0.016^{\star}$ & 0.008 & - & - \\
\hline \multicolumn{5}{|l|}{ Model 2} \\
\hline Time (per year) & $0.033^{\S}$ & 0.005 & $0.035^{\S}$ & 0.004 \\
\hline Case & - & - & $0.20^{\star}$ & 0.12 \\
\hline Case $\times$ time & $-0.018^{\dagger}$ & 0.006 & - & - \\
\hline \multicolumn{5}{|c|}{ Sensitivity analysis } \\
\hline Time (per year) & $0.027^{\S}$ & 0.006 & $0.018^{\S}$ & 0.005 \\
\hline Case & - & - & $0.51^{*}$ & 0.25 \\
\hline Case $\times$ time & $-0.021^{\dagger}$ & 0.008 & - & - \\
\hline
\end{tabular}

Multilevel longitudinal modeling was done using linear growth model. Only models with the lowest information criteria are shown. Model 1 is adjusted for age, sex, ethnicity, civil service employment grade, and body mass index. Model 2 is adjusted for the variables in model $1+$ systolic blood pressure, antihypertensive medication use, total cholesterol, HDL-cholesterol, lipid lowering medication, current smoking, leisure-time physical activity, and dietary score. Sensitivity analysis is restricted to participants with exactly two CRP measurements (181 cases, 4450 non-cases for diabetes and 22 cases, 4932 non-cases for fatal CVD) before the end of follow-up. The sensitivity analysis is adjusted for age, sex, ethnicity, civil service employment grade, and body mass index. Time, time of follow-up in years centered at the end of follow-up. Case, group indicator of controls versus fatal cardiovascular event or incident diabetes mellitus. ${ }^{\star} P<0.05,{ }^{\dagger} P<0.001,{ }^{\ddagger} P<0.001,{ }^{\S} P<0.0001$.

After further adjustment for systolic blood pressure, use of antihypertensive and lipid lowering medication, blood lipids and lifestyle characteristics, the time $\times$ event interaction remained non-significant, and the mean difference attenuated to 0.20 (s.E.M. 0.12) $\log _{2}(\mathrm{mg} / \mathrm{l})$. The sensitivity analysis on 22 cases and 4932 non-cases with two examinations of CRP replicated the parallel trajectories of log-transformed CRP levels between cases and non-cases during follow-up (Table 2). When the CRP values were back transformed, these models provided some evidence for divergence in CRP trajectories for fatal CVD cases and controls, although the 95\% confidence intervals were overlapping in the fully adjusted models (Fig. 1).

\section{Discussion}

In this prospective cohort study of a middle-aged population, we observed elevated baseline CRP levels in people who developed type 2 diabetes or died from CVD. Logarithmically transformed serum CRP values increased less steeply over time among those who developed diabetes compared with controls, leading to a smaller CRP difference at the time of diagnosis compared with the previous years. In contrast, logtransformed CRP levels followed parallel increasing linear trajectories among both CVD cases and controls.
Adjustment for potential confounders significantly attenuated the CRP differences between cases and controls for both diabetes and fatal CVD. However, it did not alter the slope difference observed between incident diabetes cases and controls.

To our knowledge, this is the first study to describe population-based trajectories of CRP levels leading up to the diagnosis of diabetes or a fatal CVD event in a large community-dwelling population. Our findings confirm previous reports that the effect of CRP on diabetes onset is markedly attenuated after adjustment for other risk factors $(1,3,5)$. In addition, we extend existing knowledge with the observation that the CRP trajectory prior to diabetes onset is characterized by a higher level of inflammation at baseline rather than a rapidly increasing level of CRP.

Several previous studies report that adjusting for obesity substantially attenuates the association of CRP with diabetes, and some studies suggest that it may even remove the association altogether $(1,3,5)$. Other components or markers of the metabolic syndrome (i.e. hypertension, dyslipidemia, glucose intolerance, liver functions, and decreased adiponectin) have also been reported to substantially attenuate the CRP-diabetes relationship (5). In concurrence with previous work, our study confirms that the high CRP levels associated with diabetes are substantially attenuated by adjustment for lipids, blood pressure, and lifestyle characteristics.

Our observations of decreasing differences in CRP levels between diabetes cases and controls do not negate a potential causal role for inflammation in the pathogenesis of diabetes. CRP might be a marker for diabetic risk factors that are present many years before the onset of diabetes, or it may be a marker for aging or other risk factors. It is also possible that CRP is a marker for an antidiabetic effect that is incrementally exhausted before diagnosis of diabetes. Other inflammatory pathways and antiinflammatory responses may be of importance in determining the risk of diabetes, as shown recently by our group (25).

The observation of elevated CRP levels and diverging CRP trajectories prior to fatal CVD confirms the validity of the multilevel model used. The temporal relationship between elevated CRP and cardiovascular outcomes including fatal cardiovascular events is well established. The Reykjavik study and a joint meta-analysis found elevated CRP values to be independently associated with later CVD events, but the authors found that 'classical' cardiovascular risk factors attenuated the association partly but not completely (9). Similarly, associations have been reported between baseline CRP levels and later fatal cardiovascular events in several populationbased observational studies, with more pronounced associations among the elderly (12).

This longitudinal approach provides an important complementary method to examine the natural history of disease development. The current study also benefits from a well-characterized, well-described cohort, and 
diagnosis of incident diabetes based largely on OGTT $(21,22)$. We applied a sophisticated approach to data analysis taking into account the interrelationship between repeated measurements from the same individual at different time points. The median follow-up time of over 10 years provided a unique opportunity to investigate the changes in CRP levels preceding diabetes and fatal CVD, and to detect a clear difference in the development of CRP levels prior to these two endpoints. We treated obesity, blood pressure, blood lipids, medications, and lifestyle measurements as timevarying variables to adjust for their baseline values and to take into account their changes during the observation period. Thus, it is unlikely that the converging CRP trajectories before diabetes development would be attributable to lifestyle changes among participants with an elevated risk for diabetes, although considerable evidence shows that medications and lifestyle interventions could decrease CRP levels in the population (25-29).

The converging findings in our main and our sensitivity analyses suggest that missing data are an unlikely source of bias in this study. However, although multilevel modeling enabled determination of CRP trajectories at a population level, with a maximum of two measurement points per person, we were unable to investigate individual trajectories or describe the exact shape of the population growth curves. The relatively low number of cases with repeated measures is also a potential drawback of the current analysis. Finally, due to the occupational and largely White nature of the study population, further research is needed to examine whether our results are generalizable to other populations.

In conclusion, this study provides novel evidence on changes in CRP before the onset of diabetes and a fatal cardiovascular event. We observed the CRP trajectory prior to diabetes onset to be characterized by a higher level of inflammation at baseline rather than a rapidly increasing level of CRP. This finding is congruent with the notion that elevated CRP levels are associated with diabetes, but argues against the notion that rapidly increasing inflammation characterizes the years preceding disease onset.

\section{Declaration of interest}

The Sponsors had no role in the design and conduct of the study; in the collection, analysis, and interpretation of the data; or in the preparation, review, or approval of the manuscript.

\section{Funding}

The presented work is funded by the Medical Research Council New Investigator Award (G0501184). The Whitehall II study is supported by the following bodies in the UK: Medical Research Council; Economic and Social Research Council; British Heart Foundation; Health and Safety Executive; Department of Health; and in the US: National Heart Lung and Blood Institute (HL36310), NIH; National Institute on
Aging (AG13196), NIH; Agency for Health Care Policy Research (HS06516); the John D and Catherine T MacArthur Foundation. M Kivimäki is supported by the Academy of Finland and the BUPA Foundation Specialist Research Grant.

\section{References}

1 Dehghan A, Kardys I, de Maat MPM, Uitterlinden AG, Sijbrands EJG, Bootsma AH, Stijnen T, Hofman A, Schram MT \& Witteman JCM. Genetic variation, C-reactive protein levels, and incidence of diabetes. Diabetes $2007 \mathbf{5 6} 872-878$.

2 Freeman DJ, Norrie J, Caslake MJ, Gaw A, Ford I, Lowe GD, O'Reilly DS, Packard CJ \& Sattar N. C-reactive protein is an independent predictor of risk for the development of diabetes in the West of Scotland Coronary Prevention Study. Diabetes 200251 1596-1600.

3 Krakoff J, Funahashi T, Stehouwer CD, Schalkwijk CG, Tanaka S, Matsuzawa Y, Kobes S, Tataranni PA, Hanson RL, Knowler WC \& Lindsay RS. Inflammatory markers, adiponectin, and risk of type 2 diabetes in the Pima Indian. Diabetes Care 200326 1745-1751.

4 Laaksonen DE, Niskanen L, Nyyssonen K, Punnonen K, Tuomainen TP, Valkonen VP, Salonen R \& Salonen JT. C-reactive protein and the development of the metabolic syndrome and diabetes in middle-aged men. Diabetologia 200447 1403-1410.

5 Lee CC, Adler AI, Sandhu MS, Sharp SJ, Forouhi NG, Erqou S, Luben R, Bingham S, Khaw KT \& Wareham NJ. Association of C-reactive protein with type 2 diabetes: prospective analysis and meta-analysis. Diabetologia 200952 1040-1047.

6 Liu S, Tinker L, Song Y, Rifai N, Bonds DE, Cook NR, Heiss G, Howard BV, Hotamisligil GS, Hu FB, Kuller LH \& Manson JE. A prospective study of inflammatory cytokines and diabetes mellitus in a multiethnic cohort of postmenopausal women. Archives of Internal Medicine 2007167 1676-1685.

7 Thorand B, Baumert J, Kolb H, Meisinger C, Chambless L, Koenig W \& Herder C. Sex differences in the prediction of type 2 diabetes by inflammatory markers: results from the MONICA/ KORA Augsburg case-cohort study, 1984-2002. Diabetes Care $200730854-860$.

8 Wannamethee SG, Sattar N, Rumley A, Whincup PH, Lennon L \& Lowe GD. Tissue plasminogen activator, von Willebrand factor, and risk of type 2 diabetes in older men. Diabetes Care 200831 995-1000.

9 Danesh J, Wheeler JG, Hirschfield GM, Eda S, Eiriksdottir G, Rumley A, Lowe GD, Pepys MB \& Gudnason V. C-reactive protein and other circulating markers of inflammation in the prediction of coronary heart disease. New England Journal of Medicine 2004350 1387-1397.

10 Shah T, Casas JP, Cooper JA, Tzoulaki I, Sofat R, McCormack V, Smeeth L, Deanfield JE, Lowe GD, Rumley A, Fowkes FG, Humphries SE \& Hingorani AD. Critical appraisal of CRP measurement for the prediction of coronary heart disease events: new data and systematic review of 31 prospective cohorts. International Journal of Epidemiology 200938 217-231.

11 Hotamisligil GS. Inflammation and metabolic disorders. Nature $2006 \mathbf{4 4 4} 860-867$.

12 Cao JJ, Arnold AM, Manolio TA, Polak JF, Psaty BM, Hirsch CH, Kuller LH \& Cushman M. Association of carotid artery intimamedia thickness, plaques, and C-reactive protein with future cardiovascular disease and all-cause mortality: the Cardiovascular Health Study. Circulation 2007116 32-38.

13 Bochud M. On the use of Mendelian randomization to infer causality in observational epidemiology. European Heart Journal $2008292456-2457$.

14 Brunner EJ, Kivimaki M, Witte DR, Lawlor DA, Davey SG, Cooper JA, Miller M, Lowe GD, Rumley A, Casas JP, Shah T, Humphries SE, Hingorani AD, Marmot MG, Timpson NJ \& Kumari M. Inflammation, insulin resistance, and diabetes Mendelian randomization using CRP haplotypes points upstream. PLoS Medicine 20085 e155. 
15 Timpson NJ, Lawlor DA, Harbord RM, Gaunt TR, Day IN, Palmer LJ, Hattersley AT, Ebrahim S, Lowe GD, Rumley A \& Smith GD. C-reactive protein and its role in metabolic syndrome: mendelian randomisation study. Lancet $20053661954-1959$.

16 Wolford JK, Gruber JD, Ossowski VM, Vozarova B, Antonio Tataranni P, Bogardus C \& Hanson RL. A C-reactive protein promoter polymorphism is associated with type 2 diabetes mellitus in Pima Indians. Molecular Genetics and Metabolism 200378 136-144.

17 Elliott P, Chambers JC, Zhang W, Clarke R, Hopewell JC, Peden JF, Erdmann J, Braund P, Engert JC, Bennett D, Coin L, Ashby D, Tzoulaki I, Brown IJ, Mt-Isa S, McCarthy MI, Peltonen L, Freimer NB, Farrall M, Ruokonen A, Hamsten A, Lim N, Froguel P, Waterworth DM, Vollenweider P, Waeber G, Jarvelin MR, Mooser V, Scott J, Hall AS, Schunkert H, Anand SS, Collins R, Samani NJ, Watkins H \& Kooner JS. Genetic Loci associated with C-reactive protein levels and risk of coronary heart disease. Journal of the American Medical Association 2009302 37-48.

18 Kivimaki M, Lawlor DA, Smith GD, Kumari M, Donald A, Britton A, Casas JP, Shah T, Brunner E, Timpson NJ, Halcox JP, Miller MA, Humphries SE, Deanfield J, Marmot MG \& Hingorani AD. Does high C-reactive protein concentration increase atherosclerosis? The Whitehall II Study PLoS ONE 20083 e3013.

19 Lawlor DA, Harbord RM, Timpson NJ, Lowe GD, Rumley A, Gaunt TR, Baker I, Yarnell JW, Kivimaki M, Kumari M, Norman PE, Jamrozik K, Hankey GJ, Almeida OP, Flicker L, Warrington N, Marmot MG, Ben-Shlomo Y, Palmer LJ, Day IN, Ebrahim S \& Smith GD. The association of C-reactive protein and CRP genotype with coronary heart disease: findings from five studies with 4,610 cases amongst 18,637 participants. PLoS ONE 20083 e 3011.

20 Zacho J, Tybjaerg-Hansen A, Jensen JS, Grande P, Sillesen H \& Nordestgaard BG. Genetically elevated C-reactive protein and ischemic vascular disease. New England Journal of Medicine 2008 359 1897-1908.
21 Marmot M \& Brunner E. Cohort profile: the Whitehall II study. International Journal of Epidemiology 200534 251-256.

22 Alberti KG \& Zimmet PZ. Definition, diagnosis and classification of diabetes mellitus and its complications. Part 1: diagnosis and classification of diabetes mellitus provisional report of a WHO consultation. Diabetic Medicine 199815 539-553.

23 Stringhini S, Sabia S, Shipley M, Brunner E, Nabi H, Kivimaki M \& Singh-Manoux A. Association of socioeconomic position with health behaviors and mortality. Journal of the American Medical Association 2010303 1159-1166.

24 Singer JD \& Willett JB. Applied Longitudinal Data Analysis: Modeling Change and Event Occurrence. New York: Oxford University Press, 2003.

25 Herder C, Brunner EJ, Rathmann W, Strassburger K, Tabak AG, Schloot NC \& Witte DR. Elevated levels of the anti-inflammatory interleukin-1 receptor antagonist (IL-1Ra) precede the onset of type 2 diabetes (Whitehall II Study). Diabetes Care 200932 $421-423$.

26 Dandona P. Effects of antidiabetic and antihyperlipidemic agents on C-reactive protein. Mayo Clinic Proceedings 200883 333-342.

27 Fung TT, McCullough ML, Newby PK, Manson JE, Meigs JB, Rifai N, Willett WC \& Hu FB. Diet-quality scores and plasma concentrations of markers of inflammation and endothelial dysfunction. American Journal of Clinical Nutrition $2005 \mathbf{8 2}$ 163-173.

28 Kasapis C \& Thompson PD. The effects of physical activity on serum C-reactive protein and inflammatory markers: a systematic review. Journal of the American College of Cardiology $2005 \mathbf{4 5}$ 1563-1569.

29 Selvin E, Paynter NP \& Erlinger TP. The effect of weight loss on C-reactive protein: a systematic review. Archives of Internal Medicine 2007167 31-39.

Received 19 April 2010

Accepted 29 April 2010 